\title{
Evaluation of the environmental performance of lime production in Cuba
}

Alexis Sagastume Gutiérrez ${ }^{1 *}$, Jo Van Caneghem², Juan B. Cogollos Martínez ${ }^{1}$, Carlo Vandecasteele ${ }^{2}$,

1: Universidad de Cienfuegos, Carretera a Rodas kilómetro 4, Cuatro caminos, Cienfuegos, Cuba.

2: Department of Chemical Engineering, University of Leuven, de Croylaan 46, B-3001 Heverlee, Belgium

*Corresponding author. Tel.: +53-43511963, fax: +53-43522762, e-mail address: asagastume@ucf.edu.cu

\section{Abstract:}

Lime production is characterized by large emissions of $\mathrm{CO}_{2}$ and by other environmental impacts. In Cuba this industry operates with outdated technology, resulting in low energy and material efficiency and in high environmental impacts. In order to improve the environmental performance of the lime industry in Cuba it is necessary to have an overview of the environmental impacts associated with the production process. This paper quantifies the environmental impacts of lime production in Cuba by means of LCA methodology in a cradle-to-gate evaluation. It also aims at establishing a benchmark for improvement by comparing the environmental impact of this industry in Cuba with a plant in an industrialized country. For the inventory evaluation the process of lime production was divided in five production stages. When necessary, the data was completed with literature sources. For the impact assessment the impacts in the following categories were considered: energy consumption, global warming, human toxicity, photoxidant formation and acidification. Results show that the calcination stage and the consumption of fuel, electricity and limestone are the main contributors to environmental impact of the production process. The economic assessment shows possibilities to improve the environmental performance while achieving cost reductions in the production process. The larger improvements in the environmental performance and cost saving can be achieved by improving the energy efficiency of the calcination stage. This can partially be accomplished with moderate investments.

Keywords: Life Cycle Assessment, Impact Assessment, Lime, quicklime

\section{Introduction}


Calcium oxide $(\mathrm{CaO})$, known as lime or quicklime, is an energy intensive product, yet one of the most widely used and cheapest alkali products employed in industry. The process of lime production involves the emission of large quantities of $\mathrm{CO}_{2}$, main actor of climate change. In fact, the production of one t of lime entails the emission of around $1.2 \mathrm{t}$ of $\mathrm{CO}_{2}[1,2]$, making lime one of the produced materials with the highest associated specific emission of $\mathrm{CO}_{2}[3,4]$.

The environmental impact of lime production can be local, regional or global in scale. Local effects include dust emissions and changes in landscape because of the mining of limestone. Emitted sulfur dioxide and nitrogen oxides contribute to acid rain on regional scale, whereas $\mathrm{CO}_{2}$ emission contributes to global climate change.

Lime industry is widespread both in developing and industrialized countries. In Cuba, lime industry consists of seven small commercial plants distributed over the country (see fig. 1). In 2004, the Cuban lime industry produced $53600 \mathrm{t}$ of lime [5], emitting about $75000 \mathrm{t}$ of $\mathrm{CO}_{2}, 0.31 \%$ of the Cuban emission of $24 \mathrm{Mt}$ of $\mathrm{CO}_{2}$ - equivalent [6].

Fig. 1. Location of lime plants in Cuba.

Lime industry in Cuba falls in the category of small and medium-sized enterprises (SMEs). Ciliberti et al. [7] analyzed corporate social responsibility in SMEs in developing countries pointing out that "SMEs that operate in developing countries face several specific challenges, e.g., lack of mentorship and skills transfer, communication gaps, lack of awareness on development opportunities and support networks, infrastructure scarcity, low saving rates and difficulties in accessing financial services". In agreement with this analysis, the lime plants exploited in Cuba operate with outdated technology and with very low to non-existing automation of the production process. Moreover, these plants are usually exploited by personnel lacking the necessary qualifications, leading to pour operation standards. These characteristics contribute to the low energy and material efficiency of this industry in Cuba. This situation causes a poor environmental performance, with specific $\mathrm{CO}_{2}$ emissions reaching values over $1.4 \mathrm{t}$ per t of lime [1,8]. Emissions of $\mathrm{CO}_{2}$, causing climate change, are one of the most serious environmental threads of our time [9]. A better utilization of resources improves competitiveness and profits, which also improve the environmental performance of a company [10].Therefore, understanding and quantifying the environmental implications associated with lime industry in Cuba will help the country on its way towards sustainability. 
Life Cycle Assessment (LCA) is an important method in modern environmental management [11] and is a useful tool to estimate the environmental impact of lime production. Application of LCA will allow the optimization of the production process by identifying its most significant impacts. Although LCA is a widespread tool, there is only limited information on LCA of lime production, the only LCA study of lime production found by the authors being the ecoinvent report No.7 [12], which gives the life cycle inventory of the lime production in KalkFabric Nestal (KFN), the only plant producing hydrated lime in Switzerland. More examples of LCA were found in the cement industry, which is closely related to lime production. Applications of LCA to products and processes can be found in literature. Huntzinger et al. [13] compared the environmental impacts of traditional Portland cement production with three alternative technologies applying a cradle-togate approach. The study identifies different possibilities to reduce the environmental impact of cement production. Valderrema et al. [14] also implement LCA with a cradle-to-gate approach to establish environmental improvements associated with the upgrade of a cement plant. The study shows important reductions of the environmental impacts of the production process because of the technological upgrade. González-García et al. [15] described the environmental impact of a non-wood based pulp production process using an LCA cradle-to-gate approach. In the study the authors collect the inventory data through on-site measurement and when necessary the data were completed with data from literature. The study identifies the hot spots of the production process showing the benefits of using renewable fuels rather than fossil fuels. Valente et al. [16] performed an extended LCA for evaluating the impacts of a woody biomass supply chain for heating plants in the alpine region assessing three main aspects of sustainability: greenhouse gas emissions, costs and direct employment potential. The study demonstrates that mountain forests are a viable source of wood fuel, which can be exploited without generating excessive impacts.

$\mathrm{CO}_{2}$ emissions during limestone calcination in a Cuban plant are discussed by Ochoa et al. [1]. The authors introduce a method to evaluate, optimize and control the thermal efficiency of lime kilns and discuss the reductions in $\mathrm{CO}_{2}$ emissions as a result of the improvement of thermal efficiency, but no further environmental implications are discussed.

An important characteristic of the lime and other industries in Cuba, and probably in other developing countries, is the lack of equipment to measure all relevant emissions. Consequently, 
it is not possible to inventory all the significant information necessary for the LCA. However, some emissions can be calculated from the mass and the energy balances of the process and the rest can be estimated with reasonable assumptions. This situation may affect the accuracy of the impact assessment. Moreover, De Benedetto and Klemes [17] indicate that in most LCA studies assumptions are made. Nevertheless, considering the current situation of the lime industry in Cuba, it seems reasonable to describe its environmental impact, even if a number of emissions have to be estimated, rather than to wait for the possibility to measure all the emissions. The outcome of the LCA is important to achieve a more environmentally friendly production of lime in Cuba.

The objective of this work is to describe, with the aid of LCA, the environmental impacts, particularly global warming, of the lime production in Cuba. Comparing the environmental indicators between different companies allows to evaluate the potential savings within a company environmental program [18]. Benchmarking is a proven tool to improve both the economic and the environmental performance of companies [19]. Moreover, in order to establish a benchmark for improvement, a plant operating with high material and energy efficiency in an industrialized country is also evaluated.

\section{Lime Production}

The flow diagram of lime production can be different from plant to plant, and generally depends on the technological characteristics of the production process in place. Nevertheless, the process includes five basic steps:

1. Quarrying of limestone

2. Limestone crushing and screening

3. Calcination of limestone

4. Hydration of quicklime and classification of hydrated lime

5. Packaging

For the sake of simplicity these steps are used to generalize the flow diagram of the production process in the plants under scope.

Fig.2. Process flow diagram of lime production

Fig. 2 shows the general flow diagram of lime production considering the associated inputs and emissions relevant for the environmental impact assessment. In the first stage, limestone is 
quarried and transferred to the crushing and screening unit to size the stones for the calcination stage. The stones with the correct size are fed to the kiln, where, with the proper supply of heat, $\mathrm{CaCO}_{3}$ dissociates into $\mathrm{CaO}$ and $\mathrm{CO}_{2}$. Quicklime is then milled and hydrated by supplying water. The obtained product goes through a classification process to increase the quality of the product. Finally, the product is packed and stored.

In general, the amount and characteristics of the process emissions depend on the plant technology, the operation standards, the raw material consumed and the fuel type. The major emissions of lime production are the gaseous emissions. The most impacting pollutants to be expected in this case are $\mathrm{CO}_{2}, \mathrm{CO}, \mathrm{SO}_{2}$ and $\mathrm{NO}_{x}$. The emissions of $\mathrm{CO}_{2}$ are from the dissociation of $\mathrm{CaCO}_{3}$ and from fuel combustion. The plant technology and operation standards strongly influence the thermal efficiency that defines the amount of $\mathrm{CO}_{2}$ emissions. The rest of the gaseous emissions are mainly influenced by the technological and operational standards of the plant rather than by the type of fuel. CO emissions are directly dependent of the burner technology and the air excess of the combustion. According to Kocabiyik [20], fuels with high sulfur content do not cause $\mathrm{SO}_{2}$ pollution in lime kilns. Finally, in limekilns temperatures usually reach values above $1300^{\circ} \mathrm{C}$; under these conditions the principal mechanism of $\mathrm{NO}_{x}$ formation is thermal- $\mathrm{NO}_{x}$ [21]. Consequently, the change of fuel type will mainly influence $\mathrm{CO}_{2}$ emissions, the rest of the gaseous emissions are mostly defined by technology and operation standards of the limekiln.

\section{Life Cycle Assessment}

Life cycle assessment is basically used for the evaluation of the environmental impacts from "cradle to grave" of both products and processes. Its application implies several benefits, including the possibility to evaluate the material and energy efficiency of the system. Also, by identifying the pollution load of the different production stages, it can provide a benchmark for improvement [13].

This study includes a 'cradle to gate' LCA of the production process of hydrated lime in Cuba. Its objective is to describe the environmental impacts, in particular global warming, of the lime industry in Cuba. It also aims to identify the possibilities for improvement by comparing the Cuban plants to the "Kalkfabrik Netstal" lime plant in Switzerland.

The LCA methodology applied in this study follows the steps outlined by the International Organization for Standardization (ISO) 14040 [13]: 
1. Determination of the assessment scope and boundaries;

2. Selection of inventory of inputs and outputs;

3. Assessment of environmental impact data compiled in the inventory; and

4. Interpretation of results and suggestions for improvement.

\subsection{Aim and scope}

The overall scope of the study includes the stages outlined in Fig. 2 . The aim is to evaluate the process of lime production in Cuba with the aid of LCA methodology using the associated environmental impacts. It also aims at identifying the possibilities to improve the environmental performance of the production process.

To this end two lime plants in Cuba with similar technological characteristics were selected. For the selected plants the most complete and reliable measurements of the considered production process in Cuba are available. To establish a benchmark for improvement Kalkfabrik Netstal (KFN) was selected, whose life cycle inventory is described in Ecoinvent Report No.7 [12]. This plant produces lime according to the highest quality standards required in the market. Also, the energy consumption of this plant is according to the state of the art of lime industry [22].

The functional unit of this study is the production of $1 \mathrm{t}$ of $\mathrm{Ca}(\mathrm{OH})_{2}$.

\subsection{Life cycle inventory}

The production output at Kalkfabrik Netstal plant consists of about $75 \%$ of quicklime containing over $96 \%$ of $\mathrm{CaO}$ and of about $25 \%$ of hydrated lime containing $97 \%$ of $\mathrm{Ca}(\mathrm{OH})_{2}$. In 2001 the annual production of this plant included $22744 \mathrm{t}$ of milled quicklime, $38324 \mathrm{t}$ of quicklime in pieces and $18275 \mathrm{t}$ of hydrated lime [12].

The plants selected in Cuba will be referred to in this work as plant No.1 and plant No.2. The entire production of these plants consists of hydrated lime. Plant No. 1 produces about $50 \mathrm{t} /$ day of hydrated lime containing $92 \%$ of $\mathrm{Ca}(\mathrm{OH})_{2}$. Plant No.2 produces about $45 \mathrm{t} /$ day of hydrated lime containing $94 \%$ of $\mathrm{Ca}(\mathrm{OH})_{2}$.

The information for the life cycle inventory of the Cuban plants was collected during a normal operation day in each plant. The emissions of dust and $\mathrm{CO}_{2}$ were obtained from the mass balance of the plants. The emission of pollutants that were not measured was estimated from literature. The life cycle inventory of KFN is described in Ecoinvent report No.7 [12] that only considers the 
information related to the production of hydrated lime and not the information regarding the production of milled and raw limestone products.

One aim of this work is to establish a benchmark for improvement by comparing the Cuban plants with the KFN plant. In this case, to obtain the possibilities to reduce the environmental impacts of lime industry in Cuba, it is assumed that the KFN plant was operating in Cuba; implying that the consumed electricity has the characteristics of its generation in Cuba rather than in Switzerland. Consequently, for the impact of electricity consumed in all considered lime plants, the average characteristics of electricity generation in Cuba are considered (see table 1),_as taken from [23, $24,25,26]$. Moreover, Swiss electricity (50\% hydroelectric [12]) is cleaner than Cuban electricity. Therefore, considering Swiss electricity for the impact of the KFN plant will results in a lower environmental impact not achievable in Cuba.

Table 1. Characteristics of the electricity generation in Cuba (per $1 \mathrm{kWh}$ )

Electricity generation in Cuba has high emissions of $\mathrm{SO}_{2}$ entailing a high impact on acidification. For the impacts of the explosives used in the quarry and the paper bags used for packaging the final product, the life cycle inventories provided by the LCA software Simapro 7.3 are considered.

\subsubsection{Mass balance of Cuban plants.}

The inventory of the material and energy flows in the Cuban plants is used to develop the mass balance of the production process. The balance is made for the processing of the raw material from the quarry to the packing stage (Fig. 3). The main objective of the mass balance is to determine the specific consumptions of raw material of the process to produce $1 \mathrm{t}$ of $\mathrm{Ca}(\mathrm{OH})_{2}$. It is also used to establish the mass of waste generated in the classification process and to indirectly calculate the emissions of dust.

Fig. 3. Mass balance of Cuban plant No.1 per $t$ of $\mathrm{Ca}(\mathrm{OH})_{2}$

Fig. 3 shows the mass balance of plant No.1. In this case, the production of $1 \mathrm{t}$ of $\mathrm{Ca}(\mathrm{OH})_{2}$ requires the extraction of $2.85 \mathrm{t}$ of limestone from the quarry to be transported to the production facility. Once the limestone reaches the plant it is fed to the crushing and screening stage from where $1.71 \mathrm{t}$ are fed to the kiln and the remaining $1.14 \mathrm{t}$ are classified as construction materials because they do not meet the dimension requirements of the kiln. In the calcination stage a fraction of the stone processed dissociates into $0.68 \mathrm{t}$ of $\mathrm{CO}_{2}$ and $0.87 \mathrm{t}$ of $\mathrm{CaO}$ remaining $0.15 \mathrm{t}$ as $\mathrm{CaCO}_{3}$. The $\mathrm{CaO}$ and $\mathrm{CaCO}_{3}$ are fed to the hydration and classification unit, where $\mathrm{CaO}$ is hydrated with water 
to yield $1.15 \mathrm{t}$ of $\mathrm{Ca}(\mathrm{OH})_{2}$. From this, $0.17 \mathrm{t}\left(0.10 \mathrm{t}\right.$ of $\mathrm{Ca}(\mathrm{OH})_{2}$ and $0.07 \mathrm{t}$ of $\left.\mathrm{CaCO}_{3}\right)$ is wasted in the classification process and $0.05 \mathrm{t}$ of $\mathrm{Ca}(\mathrm{OH})_{2}$ are lost to the environment. Finally, the packing unit receives $1 \mathrm{t}$ of $\mathrm{Ca}(\mathrm{OH})_{2}$ and $0.09 \mathrm{t}$ of $\mathrm{CaCO}_{3}$. The mass balance of plant $\mathrm{No} .2$ is similar to that of plant No.1.

The mass balance of the production in KFN is also established based on the inventory given by ecoinvent report No. 7 [12].

Fig. 4. Mass balance of KalkFabric Nestal per $\mathrm{t}$ of $\mathrm{Ca}(\mathrm{OH})_{2}$

Fig. 4 shows that in the case of $\mathrm{KFN}$, the production of $1 \mathrm{t}$ of $\mathrm{Ca}(\mathrm{OH})_{2}$ requires the extraction of 2.03 t of limestone from the quarry to be transported to the production facility. From the crushing and screening stage $1.37 \mathrm{t}$ are fed to the kiln and the remaining $0.66 \mathrm{t}$ are classified as construction materials. In the calcination $0.76 \mathrm{t}$ of $\mathrm{CaO}$ and $0.60 \mathrm{t}$ of $\mathrm{CO}_{2}$ is obtained, the remaining $0.03 \mathrm{t}$ are the impurities of the limestone. The $\mathrm{CaO}$ is fed to the hydration and classification unit, where $\mathrm{CaO}$ is hydrated with water to yield $1 \mathrm{t}$ of $\mathrm{Ca}(\mathrm{OH})_{2}$ plus $0.03 \mathrm{t}$ of impurities that go to the packing.

Comparing the results shown in figures 3 and 4 the higher material efficiency of KFN compared with plant No. 1 is evident. The Cuban plant shows a $25 \%$ higher consumption of limestone in the calcination stage than KFN. It also generates important amounts of wastes and dust containing $\mathrm{Ca}(\mathrm{OH})_{2}(0.15 \mathrm{t}$ are wasted in this stage) .

The classification process is intended to enhance the quality of the final product. This may involve the reduction of particle size or the segregation of unburnt lime, free $\mathrm{CaO}$ and hydrated lime. In the hydration and classification stage at the KFN plant no waste is generated according to [12]. In the classification process, the oversize particles rejected consist of varying proportions of unburnt limestone, hydrated lime and gritty hydrate [27]. They are generally processed in three ways [27]:

1. Rejected particles are milled and then fed to a secondary air classifier. The resulting fine fraction (secondary fines) are either blended with primary fines or used to produce a less pure grade of hydrated lime. The coarse fraction from the secondary classifier is recycled to the mill.

2. If the secondary fines contain unacceptable amounts of free $\mathrm{CaO}$, they may be recycled to the hydrator. 
3. If the fines contain high amounts of $\mathrm{CaCO}_{3}$, various options exist to segregate the $\mathrm{CaCO}_{3}$ rich fraction. The latter fraction can be sold as agricultural lime.

The KFN plant produces high quality hydrated lime with little impurities [12]. The classification process in this case uses an air separator circuit to remove the finest particles that are recovered in a cyclone and then transferred to the storage and packing unit. The coarse particles from the first circuit are conducted to a second circuit where they are milled in a hammer mill and recovered in a similar air separator and cyclone combination. This product is sold as a less fine hydrated lime.

In the case of plant No.1, the hydrated lime produced contains many impurities (mainly $\mathrm{CaCO}_{3}$ ). The classification process in this case is intended to remove the $\mathrm{CaCO}_{3}$ rich fraction from the final product with a cyclone. Only one separation stage with a cyclone separator is implemented in plant No.1; no further recycling of the wastes flow is implemented.

\subsubsection{Estimated emissions for Cuban plants.}

A number of relevant emissions have to be estimated to complete the inventory. Specialized literature reports ranges of emissions for the relevant pollutants emitted during the production process. For the Cuban plants the most likely emission values according to their process characteristics were considered. Emission values are shown in Table 2.

Table 2. Estimated emission values for Cuban plants.

The size distribution of the particulate emissions is assumed to be [12]: $50 \%$ below $10 \mu \mathrm{m}, 45 \%$ between $10 \mu \mathrm{m}$ and $2.5 \mu \mathrm{m}$ and $5 \%$ below $2.5 \mu \mathrm{m}$. The emission of dust in stage 4 is not taken from literature, but calculated from the mass balance in section 3.2.1.

\subsection{Inventory analysis.}

The inventory assessment of the plants considered in this study reveals important differences in the diesel and electricity consumption and also in the dust emission between Cuban plants and KFN plant. Table 3 shows the life cycle inventory for the three lime plants.

Table 3. Energy and emissions inventory of the production stages (per t of $\mathrm{Ca}(\mathrm{OH})_{2}$ ).

The difference in the diesel consumption ( 5 times higher at Cuban plants) is explained by the low energy efficiency of the outdated technology used in the quarrying stage in Cuba plants. The higher electricity consumption of KFN plant (1.5 times) compared to Cuban plants is related with the low level of automation of Cuban plants, implying that some processes like packaging, are 
carried out manually, entailing lower electricity consumption. The difference in the dust emissions is due to the loss of product in the hydration and classification stage in Cuban plants. These cause emissions several times higher than the emissions reported at KFN plant.

\section{LCA results}

The environmental impact was evaluated according to the CML ("Centrum voor Milieuntechnologie Leiden" - Institute of Environmental Sciences of the University of Leiden) method developed by the Institute of Environmental Sciences at the University of Leiden [28]. This results in the definition of an environmental profile of the process evaluated by quantifying the environmental impacts in different impact categories.

Considering that lime production is energy intensive and is characterized by the emissions of $\mathrm{CO}_{2}, \mathrm{CO}, \mathrm{NOx}, \mathrm{SO}_{2}$ and dust $[2,27]$, in this study the impacts in the following impacts categories were analyzed:

1. Energy consumption (EC)

2. Acidification $(\mathrm{A})$

3. Global warming (GW)

4. Human toxicity $(\mathrm{HT})$

5. Photo-oxidant formation (POF)

The environmental impacts per impact category for the three lime plants are shown in Table 4.

Table 4. Impact assessment of the lime production process (per t of $\left.\mathrm{Ca}(\mathrm{OH})_{2}\right)[29]$ )

Table 4 shows that in general, the production of hydrated lime in Cuba has an important environmental impact. As expected for plants with low energy efficiency, the energy consumption and the impact in the category global warming is high, with average values of 1.2 and 1.4 times the impact of KFN. The low energy efficiency also affects the impact on photoxidant formation with an average impact that is 4.8 times higher than the KFN impact.

Also the low material efficiency negatively influences the environmental performance of Cuban plants. The loss of product to the environment in the plants provokes large emissions of dust, increasing the impact in the category human toxicity to 7.7 times the impact of KFN. In the category human toxicity plant No. 2 generates an impact $32 \%$ higher than plant No. 1 , for plant No.2 larger emissions of dust are due to larger leaks in the transport system. 
As expected, the impact in the category acidification is very low. According to [20, 27], $\mathrm{SO}_{2}$ emissions are generally very low in vertical lime kilns, which typically retain between $70 \%$ and $90 \%$ of the sulfur of the fuel. The higher impact observed for KFN compared with Cuban plants is explained by the higher electricity consumption at KFN. The characteristics of the electricity generation considered in the LCA entail high emissions of $\mathrm{SO}_{2}$ (see table 1), implying a high impact in the category acidification.

These results highlight the main environmental issues of the lime production in Cuba. However, in order to improve the environmental performance of this industry, it is necessary to identify the sources of pollution. Furthermore, the contributions of the different production stages in the considered impact categories must be highlighted. Figures 5, 6 and 7 show, for KFN and for the Cuban plants the relative contribution of the different production stages to the considered impact categories.

Fig. 5. Relative contributions per production stage to each impact category at KFN

Fig. 5 shows that for 4 of the 5 impact categories the calcination stage has the highest impact in the production process in KFN. This stage accounts for $97 \%$ of the energy consumption, $83 \%$ of the impact in the category acidification, $99 \%$ of the impact in the category global warming, $9 \%$ of the impact in the category human toxicity and $88 \%$ to the impact in the category photoxidant formation. Other contributions are: hydration and classification accounting for $12 \%$ to the total impact in the category acidification, quarrying accounting for $22 \%$ and packaging accounting for $68 \%$ of the total impact in the category human toxicity.

Fig. 6. Relative contribution per production stage to each impact category in plant No.1

Fig. 6 shows the relative contribution of each production stage in plant No.1 to the considered impact categories. In this case, calcination remains the most impacting stage of lime production. This stage accounts for $94 \%$ of the energy consumption, $82 \%$ of the impact in the category acidification, $99 \%$ of the impact in the category global warming, $98 \%$ to the impact in the category photoxidant formation and $6 \%$ of the impact in the category human toxicity. Unlike in the KFN plant the packaging stage is not the main contributor to the impact in the category human toxicity. In this case the most important contributor is the hydration and classification stage accounting for $71 \%$ of the impact in the category human toxicity and $13 \%$ of the impact in the category acidification. 
Fig. 7. Relative contribution per production stage to each impact category in plant No.2

Fig. 7 shows for plant No. 2 the relative contribution of each production stage to the considered impact categories. Like plant No. 1 and KFN, calcination remains the production stage with the highest environmental impact. This stage accounts for $92 \%$ of the energy consumption, $80 \%$ of the impact in the category acidification, $99 \%$ of the impact in the category global warming, $97 \%$ of the impact in the category photoxidant formation and $5 \%$ of the impact in the category human toxicity. Like plant No.1, the hydration and classification stage is the main contributor to the impact in the category human toxicity accounting for $79 \%$ of the impact in this category and for $13 \%$ of the impact in the category acidification. The higher relative contribution of the hydration and classification stage for Cuban plants, compared to KFN is explained by the loss of product to the environment (emission of dust).

Considering the results, it can be concluded that the calcination stage is determining for the environmental performance of a lime plant. Also, the results obtained for the Cuban plants stress the need for a better control of the product loss to the environment in the hydration and classification stage. This can drastically reduce the impact of the process in the category human toxicity.

The environmental impact of a production process depends on the consumption of resources and the amount of pollutants emitted during the process. The emission of pollutants is directly related with the energy and material consumption of the process: the higher the energy and material efficiency of the process is, the lower is the emission of pollutants and vice versa. For example, fuel consumption entails the emission of $\mathrm{CO}, \mathrm{CO}_{2}, \mathrm{SO}_{2}$ and $\mathrm{NO}$. Therefore, fuel consumption contributes to the impact in the categories of energy consumption, global warming, acidification, human toxicity and photoxidant formation. Consequently, identifying the relation between consumption and environmental impact will also highlight the allocation of the pollution source and help to address the environmental performance of the process. Figures 8,9 and 10 show, for KFN and for Cuban plants the relative contribution of each input to the different impact categories.

Fig. 8. Relative contribution of each input per impact category in KFN

Fig. 8 shows that, for KFN, fuel and electricity consumption accounts for the largest contribution to the process impact. Fuel consumption accounts for $76 \%$ of the energy consumption, $17 \%$ of the impact in the category acidification, $21 \%$ of the impact in the category global warming, $9 \%$ of 
the impact in the category human toxicity and $39 \%$ of the impact in the category photoxidant formation. The electricity consumption accounts for $23 \%$ of the energy consumption, $82 \%$ of the impact in the category acidification and $61 \%$ of the impact in the category photoxidant formation. The contribution of the limestone consumption is also important and accounts for $75 \%$ of the impact in the category global warming.

Fig. 9. Relative contribution of each input per impact category in plan No.1

Fig. 9 shows the relative contribution of each input to the impact categories for plant No.1. In this case the fuel consumption accounts for $89 \%$ of the energy consumption, $62 \%$ of the impact in the category acidification, $27 \%$ of the impact in the category global warming and $95 \%$ of the impact in the category photoxidant formation. These results represent an increase of the relative contribution of fuel consumption to the process impacts compared with the KFN plant. The electricity consumption in Cuban plant No 1 accounts for $8 \%$ of the energy consumption and contributes for $35 \%$ to the impact in the category acidification. The limestone consumption accounts for $71 \%$ of the impact in the category global warming and for $74 \%$ of the impact in the category human toxicity. The consumption of packing bags accounts for $16 \%$ of the impact in the category human toxicity.

Fig. 10. Relative contribution of each input per impact category in plan No.2

Fig. 10 shows the relative contribution of each input to the impact categories for plant No.2. In this case the fuel consumption accounts for $86 \%$ of the energy consumption, for $58 \%$ of the impact in the category acidification, for $27 \%$ of the impact in the category global warming and for $94 \%$ of the impact in the category photoxidant formation. The electricity consumption accounts for $10 \%$ of the energy consumption and contributes with $39 \%$ to the impact in the category acidification. The limestone consumption accounts for $71 \%$ of the impact in the category global warming and for $81 \%$ of the impact in the category human toxicity. The packing bags consumption accounts for $12 \%$ of the impact in the category human toxicity. The higher relative contribution of the fuel and limestone consumption to the different impact categories of Cuban plants is in general related with their low energy and material efficiency.

To further clarify the key factors related to the environmental performance of a lime plant, the inputs with the highest contribution are identified, within the stages with the highest impacts in each environmental impact category. 
Fig. 11. Relative contributions to the impact in the different impact categories of the most relevant stages and the most significant associated inputs in KFN plant (the numbers within brackets stand for the stages of the process).

Fig. 11 shows the most significant inputs for each of the stages that contribute most for the different impact categories considered for KFN. In agreement with figure 5 the calcination stage accounts for $97 \%$ of the total energy consumption, for $76 \%$ of the fuel consumption and for $21 \%$ of the electricity consumption. Calcination accounts for $83 \%$ of the total impact in the impact category acidification, for $66 \%$ of the impact related to electricity consumption and for $17 \%$ of the impact related to fuel consumption. The calcination stage also accounts for $99 \%$ of the total impact in the impact category climate change, for $79 \%$ of the impact related to the limestone consumption, for $17 \%$ related to fuel consumption and for $3 \%$ related with the electricity consumption. The impact in the impact category human toxicity comes from both the packaging stage, accounting for $68 \%$ of the total impact (related to the consumption of packing bags), and the quarrying stage, accounting for $27 \%$ of the total impact $(17 \%$ related to explosives consumption and $6 \%$ related to limestone blasting). Finally, for the impact category photo-oxidant formation, the calcination stage accounts for $88 \%$ of the total impact, with $49 \%$ related to electricity consumption and $39 \%$ related to fuel consumption.

Fig. 12. Relative contributions to the impact in the different impact categories of the most relevant stages and the most significant associated inputs in plant No. 1 (the numbers within brackets stand for the stages of the process).

Fig. 12 shows the most significant inputs for each of the most contributing stages for the different impact categories considered for plant No.1. In agreement with figure 6, the calcination stage accounts for $94 \%$ of the total energy consumption, with $89 \%$ of the impact related to fuel consumption and $5 \%$ related to electricity consumption. Calcination accounts for $83 \%$ of the total impact in the impact category acidification, with $62 \%$ of the impact related to fuel consumption and $20 \%$ of the impact related to electricity consumption. For the impact in the impact category climate change, the calcination stage accounts for $98 \%$ of the total impact, with $68 \%$ of the impact related to limestone consumption, $34 \%$ related to fuel consumption and $1 \%$ related to electricity consumption. The impact in the impact category human toxicity, in this case, comes from the hydration and classification stage accounting for $71 \%$ of the impact (related to limestone 
consumption), from the packaging stage accounting for $16 \%$ of the total impact (related to consumption of packing bags) and the quarrying stage accounting for $6 \%$ of the total impact (related to explosives consumption). Finally, for the impact category photo-oxidant formation, the calcination stage accounts for $98 \%$ of the total impact, with $95 \%$ related to fuel consumption and $3 \%$ related to electricity consumption.

\section{Economic costs associated with the environmental behavior of Cuban plants.}

As discussed in the previous section, a number of impacts identified in the Cuban plants are associated with its energy and material efficiency. The energy and material efficiency of a lime plant are directly associated with its economic performance. Therefore, reducing the environmental impact of these plants in Cuba will not only give an environmental benefit, but also an economic one. To highlight the economic implications associated with the environmental performance of the lime production in Cuba a simple economic evaluation is made. In this case the impact related to the energy and material efficiency of the production process is assessed. In particular, the saving potential related to the emission of $\mathrm{CO}$ and $\mathrm{CO}_{2}$ in the calcination stage and the emission of the dust in the hydration and classification stage is evaluated. These emissions mainly influence the impact categories of:

1. Energy consumption

2. Global Warming

3. Human Toxicity

4. Photoxidant Formation

For the calculations the costs of fuel oil is considered $0.60 \$ / l$, for diesel $1.10 \$ / l$ and for electricity $0.10 \$ / \mathrm{kWh}$. The investment, amortization and maintenance costs are not considered here. Table 5 shows the production cost of $1 \mathrm{t}$ of $\mathrm{Ca}(\mathrm{OH})_{2}$ calculated for the Cuban plants and for KFN according to the inventory of table 3 .

Table 5. Production cost of $1 \mathrm{t}$ of hydrated lime.

In order to develop the economic evaluation, first the possibilities to reduce the emissions of $\mathrm{CO}$, $\mathrm{CO}_{2}$ and dust are determined by comparing the inventory of the KFN plant with the inventories of the Cuban plants. In this way the possibilities to increase the production of hydrated lime and to reduce the fuel consumption and the emissions $\mathrm{CO}, \mathrm{CO}_{2}$ and dust are established. Finally, the 
economic cost associated with the reduction of fuel consumption or the increase of hydrated lime production is calculated.

First the improvements of the energy efficiency are considered. As the most important energy consumption is located in the calcination stage, only the improvements regarding this stage are considered. Two factors affect the energy efficiency during calcination: the combustion efficiency (related with the $\mathrm{CO}$ emissions) and the overall thermal performance of the kiln, directly related with the fuel consumption and the $\mathrm{CO}_{2}$ emissions. The cost associated with the emissions of $\mathrm{CO}$ and $\mathrm{CO}_{2}$ are considered separately.

A high concentration of $\mathrm{CO}$ in the combustion gases is indicative of low combustion efficiency. By comparing the combustion efficiency of the Cuban plants (measured by the emissions of CO considered) with the combustion efficiency of KFN (according to the CO emissions reported in [12]) the thus achievable reduction of the $\mathrm{CO}$ emission and of fuel consumption can be established. Finally, the achievable economic savings and the possible reduction of the environmental impact on the different impact categories are calculated. Reducing the CO emissions may require a better control of the air excess supplied to combustion and even the replacement of the burner technology. Table 6 shows the results.

Table 6. Saving potential associated with reduction of $\mathrm{CO}$ emission.

Table 6 shows that on average the $\mathrm{CO}$ emission of the Cuban plants can be reduced by about $76 \%$ if the same combustion efficiency as in the KFN plant would be obtained. This would reduce the associated impact on photoxidant formation by more than $83 \%$. Also the fuel consumption would decrease reducing the energy consumption by $11 \%$ and the impact in the category global warming by $4 \%$. This would also give a reduction of the production cost by about $10 \%$.

Another possibility to reduce the fuel consumption of the plant is the optimization of the thermal process in the calcination stage, which will reduce the emissions of $\mathrm{CO}_{2}$ per $\mathrm{t}$ of $\mathrm{Ca}(\mathrm{OH})_{2}$ produced. When the energy efficiency of the calcination stage of Cuban plants is compared to the efficiency of, KFN a great potential for improvement appears. Reducing the $\mathrm{CO}_{2}$ emissions implies the optimization of the thermal process of the kiln (better control of the fuel and limestone supply to the kiln, of the size distribution of the stones fed to the kiln, etc.). Table 7 shows the potential reduction of the fuel consumption and the associated $\mathrm{CO}_{2}$ emission.

Table 7. Saving potential associated with the emission of $\mathrm{CO}_{2}$. 
The results in table 7 imply that the potential to reduce the $\mathrm{CO}$ emissions, discussed in table 6 , is already implemented. Results in table 7 show a potential to reduce, on average for both plants, $31 \%$ of the fuel consumption implying a decrease of $28 \%$ of the production costs. These reductions also entail a decrease of $10 \%$ of the impact in the category global warming and of $29 \%$ of the total energy consumption.

The results shown in tables 6 and 7 highlight the synergy between costs savings and reduction of environmental impacts in the calcination stage. This stage is the highest contributor to the environmental impacts of a lime plant and fuel consumption is the most influencing factor. Fuel consumption also accounts for more than $80 \%$ of the operation costs in the analyzed plants. Therefore, improving the energy efficiency of lime production implies, as shown in tables 6 and 7, important costs savings and substantial reductions of the environmental impact of the overall production process.

The economic aspects related to the material efficiency of the production process are most important in the hydration and classification stage because of the significance of the dust emission and the waste generation in this stage. Table 8 shows the potential to improve the economic performance of the plant and to reduce the impact in the category human toxicity caused by the dust emissions.

Table 8. Saving potential associated with the loss of product

Table 8 shows the significance of the product loss in Cuban plants. In plant No.1, dust emission causes $34 \%$ of the total losses of $\mathrm{Ca}(\mathrm{OH})_{2}$, the rest is lost as waste during the classification process. In the plant No.2 the dust emission is related to $99 \%$ of the total loss. Elimination of the losses of product implies a reduction of $75 \%$ and $83 \%$ of the impact in the category human toxicity for plant No.1 and plant No.2. The improvement of the material efficiency also entails a reduction of $13 \%$ and $7 \%$ of the production cost for plant No.1 and plant No. 2 .

The potential reductions detected for Cuban plants can be achieved by improving the operation standards or through economic investments to modify or change the technology under exploitation in these plants.

Reducing the emissions of $\mathrm{CO}$ in Cuban plants may imply a change in the kiln burners and the implementation of the preheating of the combustion air. This represents a viable economic investment for Cuban plants with attractive benefits. On the other hand, reducing the emissions 
of $\mathrm{CO}_{2}$ can only be partially achieved by improving the operation standards of the kiln. Further reductions necessitate important technological changes implying high investments precluded for this industry in Cuba.

The improvement of the material efficiency should consider the potential to reduce the material loss to the environment and in the classification stage. In this case an important reduction, even the complete elimination of the material loss to the environment, is achievable. This implies a viable investment with attractive benefits for Cuban plants. The material loss with the classification process is an issue only for plant No.1; plant No.2 losses only small quantities of product in this process. According to the characteristics of the classification process in plant No.2, improving this process in plant No.1 is possible at reasonable investment costs.

\section{Conclusions}

The results of the Life Cycle Assessment applied to the lime production in Cuba show that this industry entails an important environmental impact. This study indicates that the calcination stage and the consumption of fuel, electricity and limestone are the most important factors in the environmental impact of a lime plant. It also highlights the influence of the material loss to the environment on the impact in the category human toxicity in Cuban plants.

This work also discusses some measurements to reduce the environmental impact of the lime production in Cuba. In particular the possibilities to reduce the emissions of $\mathrm{CO}, \mathrm{CO}_{2}$ and dust and the possibilities to implement such reductions are discussed. Reducing the emission of CO and dust can be achieved with viable investments and attractive economic and environmental benefits. Further improvements of the environmental performance can be achieved by reducing $\mathrm{CO}_{2}$ emissions. This can only be partially achieved by improving the operation standards; further improvements require a technological upgrade implying important economic investments. Upgrading the lime production in Cuba to the state of the art of this industry entails the introduction of sophisticated instruments and equipment and also the use of automatic control of several parameters of operation and a technological change implying important economic investments. The acquisition cost of this kind of technology is high, and in general developing countries do not have access to it. In addition the small size of lime factories in Cuba precludes important investments, changes in technology or changes in equipment. The potential of improvements in Cuban plants must be studied more deeply, especially the potential to reduce fuel consumption 
in the calcination stage. The savings obtained by implementing such improvements can help to acquire automation technology that can further improve the process performance from both the economic and the environmental point of view. The implementation of the achievable partial improvements in Cuban plants will not upgrade this industry to the state of the art, but can significantly reduce the environmental impact of this industry with attractive economic benefits. In general, this study provides information that helps to improve the environmental performance of small lime plants in developing countries.

\section{Acknowledgement}

The authors like to gratefully acknowledge to academic fellowships' fund VEWA (Association of Educative and Scientific Authors) for their support to researchers of developing countries.

\section{References}

1. Ochoa, P. A., Sagastume, A., Cogollos, J. B., Vandecasteele, C., 2010. Cleaner production in a small lime factory by means of process control. Journal of Cleaner Production.18, 1171-1176.

2. European Commission, 2001. Integrated Pollution Prevention and Control (IPPC). Reference Document on Best Available Techniques in the Cement and Lime $\begin{array}{llll}\text { Manufacturing } & \text { Industries. }\end{array}$ www.epa.ie/downloads/advice/brefs/cement.pdf (20.11.2011)

3. Hoening, V., Schneider M., 2002. The effects of CO2 emissions trading on energy intensive sector industry. ZKG International. 55, 64-73.

4. Wolter, A., Fuchs, W., 2007. Specific CO2 emissions and the applications of lime burning kilns. ZKG International. 60, 45-50.

5. Bermúdez-Lugo, O., 2008. The Mineral Industry of Cuba. U.S. geological survey, minerals yearbook.

6. ONE. Cuba. Gross emission of Greenhouse gases. La Habana, Cuba. Available from: www.one.cu/aec2010/esp/02_tabla_cuadro.htm (20.11.2011)

7. Ciliberti, F., Pontrandolfo, P., Scozzi, B., 2008. Investigating corporate social responsibility in supply chains: a SME perspective. Journal of Cleaner Production. 16, 1579-1588. 
8. Sagastume, A., Vandecasteele, C., 2011. Exergy-based indicators to evaluate the possibilities to reduce fuel consumption in lime production. Energy. 36, 2820-2827.

9. Benhelal, E., Zahedi, G., Hashim, H., 2012. A novel design for green and economical cement manufacturing. Journal of Cleaner Production. 22, 60-66.

10. Strazza, C., Del Borghi, A., Gallo, M., Del Borghi, M., 2011. Resource productivity enhancement as means for promoting cleaner production: analysis of co-incineration in cement plants through a life cycle approach. Journal of Cleaner Production. 19, 16151621.

11. Löfgren, B., Tillman, A., Rinde, B., 2011. Manufacturing actor's LCA. Journal of Cleaner Production. 19, 2025-2033.

12. Kellenberger, D., Althaus H. J., Jungbluth, N., Kunniger, T., Lehmann, M., Thalmann, P., Ecoinvent report No.7, 2007 .Life cycle inventories of building products. Final report ecoinvent data v2.0 No.7. EMPA Dunbendorf, Swiss Centre for life cycle inventories, Dubendorf, $\mathrm{CH}$.

13. Huntzinger, D. N., Eatmon, T. D., 2009. A life-cycle assessment of Portland cement manufacturing: comparing the traditional process with alternative technologies. Journal of Cleaner Production 17, 668-675.

14. Valderrama, C., Granados, R., Cortina, J. L., Gasol, C. M., Guillem, M., Josa, A., 2012. Implementation of best available techniques in cement manufacturing: a life-cycle assessment study. Journal of Cleaner Production. 25, 60-67.

15. González-García, S., Moreira, M. T., Artal, G., Maldonado, L., Feijoo, G., 2010. Environmental impact assessment of non-wood based pulp production by sodaanthraquinone pulping process. Journal of Cleaner Production. 18, 137-145.

16. Valente, C., Spinelli, R., Hillring, B. G., 2011. LCA of environmental and socio-economic impacts related to wood energy production in alpine conditions: Valle di Fiemme (Italy). Journal of Cleaner Production. 19, 1931-1938

17. De Benedetto, L., Klemes, J., 2009. The Environmental Performance Strategy Map: an integrated LCA approach to support the strategic decision-making process. Journal of Cleaner Production. 17, 900-906. 
18. Jasch, C., 2000. Environmental performance evaluation and indicators. Journal of Cleaner Production. 8, 79-88.

19. Altham, W., 2007. Benchmarking to trigger cleaner production in small businesses: drycleaning case study. Journal of Cleaner Production. 15, 798-813.

20. Kocabiyik, S., 2007. Impact of the fuel quality in lime kilns on air pollution by SO2. ZKGInternational. 60, 74-81.

21. Werther, J., Ogada, T., 1999. Sewage sludge combustion. Progress in Energy and Combustion Science. 25, 55-116.

22. Harder, J., 2007. Market demands and trends in the lime industry. ZKG International. 60, 45-55.

23. Turtós, L., Meneses, E., Sánchez, M., Rivero, J., Díaz, N., 2007. Assessment of the impacts on health due to the emissions of Cuban power plants that use fossil fuel oils with high content of sulfur. Estimation of external costs. Atmospheric Environment. 41, 2202-2213.

24. Pérez, D., López, I., Berdellans, I., 2005. Evaluation of energy policy in Cuba using ISED. Natural Resources Forum. 29, 298-307.

25. ONE. Cuba. Specific fuel consumption in public utilities enterprises (basic ratio: 10000 $\mathrm{kcal} / \mathrm{kg})$. Enero-Diciembre de 2009. Available from: www.one.cu (20.11.2011)

26. Colás, J. A., Alvarez, O. H., Quevedo, E. F., Teutelo, R., 2006. Evaluación de las emisiones gaseosas e impacto ambiental de una termoeléctrica cubana. Ecosolar 17. Available from: www.cubasolar.cu/biblioteca/Ecosolar/Ecosolar17/HTML/articulo03.htm (20.11.2011)

27. Oates, J. A. H., 1998. Lime and Limestone: Chemistry and Technology, Production and Use, WILEY-VCH, Weinheim, Federal Republic of Germany.

28. Guinée, B.J., Gorrée, M., Heijungs, R., Huppes, G., Kleijn, R., de Koning, A., van Oers, L., Wegener Sleeswijk, A., Suh, S., Udo de Haes, H.A., de Bruijn, H., van Duin, R., Huijbregts, M.A.J., 2002. Handbook on life cycle assessment - operational guide to the ISO standards. Kluwer Academic Publishers, Dordrecht, Netherlands.

29. CML database. Available from: www.leidenuniv.nl/cml/ssp/index.html (20.11.2011) 
Figures

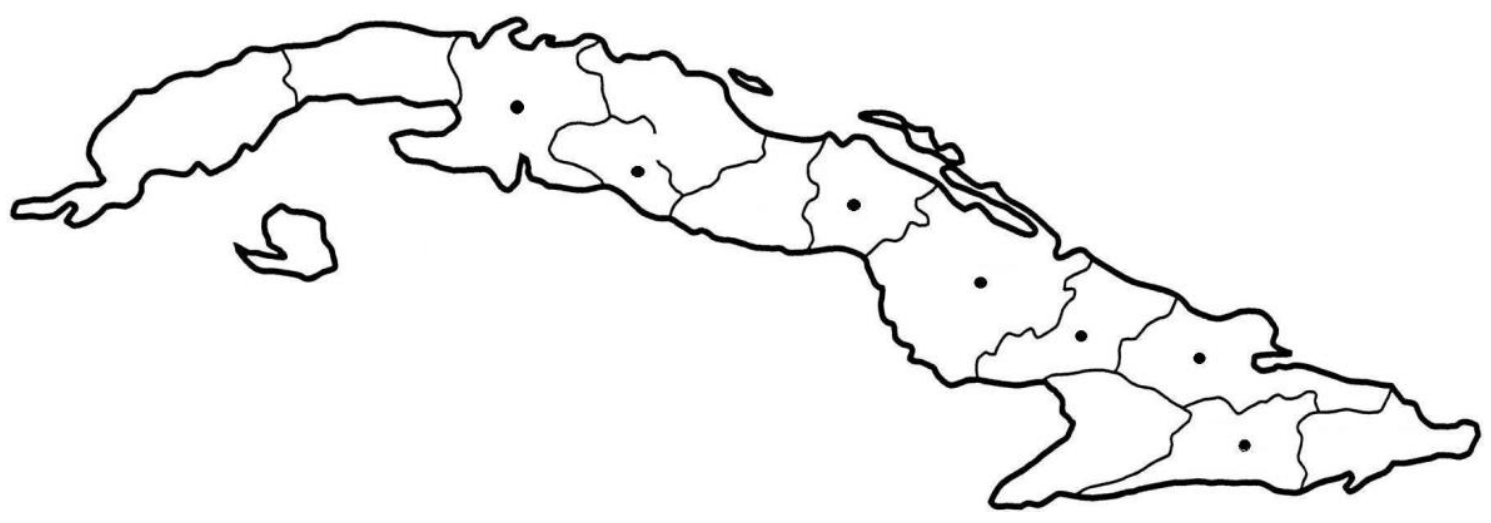

Fig. 1. Location of lime plants in Cuba.

\begin{tabular}{|llll|}
\hline \multicolumn{2}{|c|}{ Inputs: } & & Outputs: \\
D Diesel & F & Fuel oil & (1) Dust emissions \\
E Electricity & P & Packing bags & (2) Gaseous emissions \\
W W Water & & (3) Waste bags
\end{tabular}

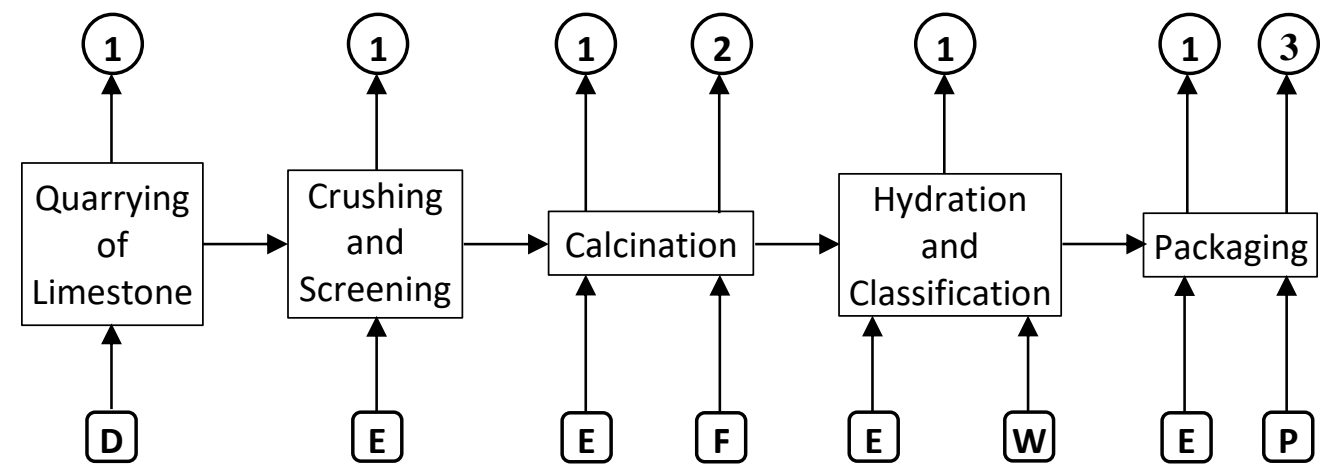

Fig.2. Process flow diagram of lime production 


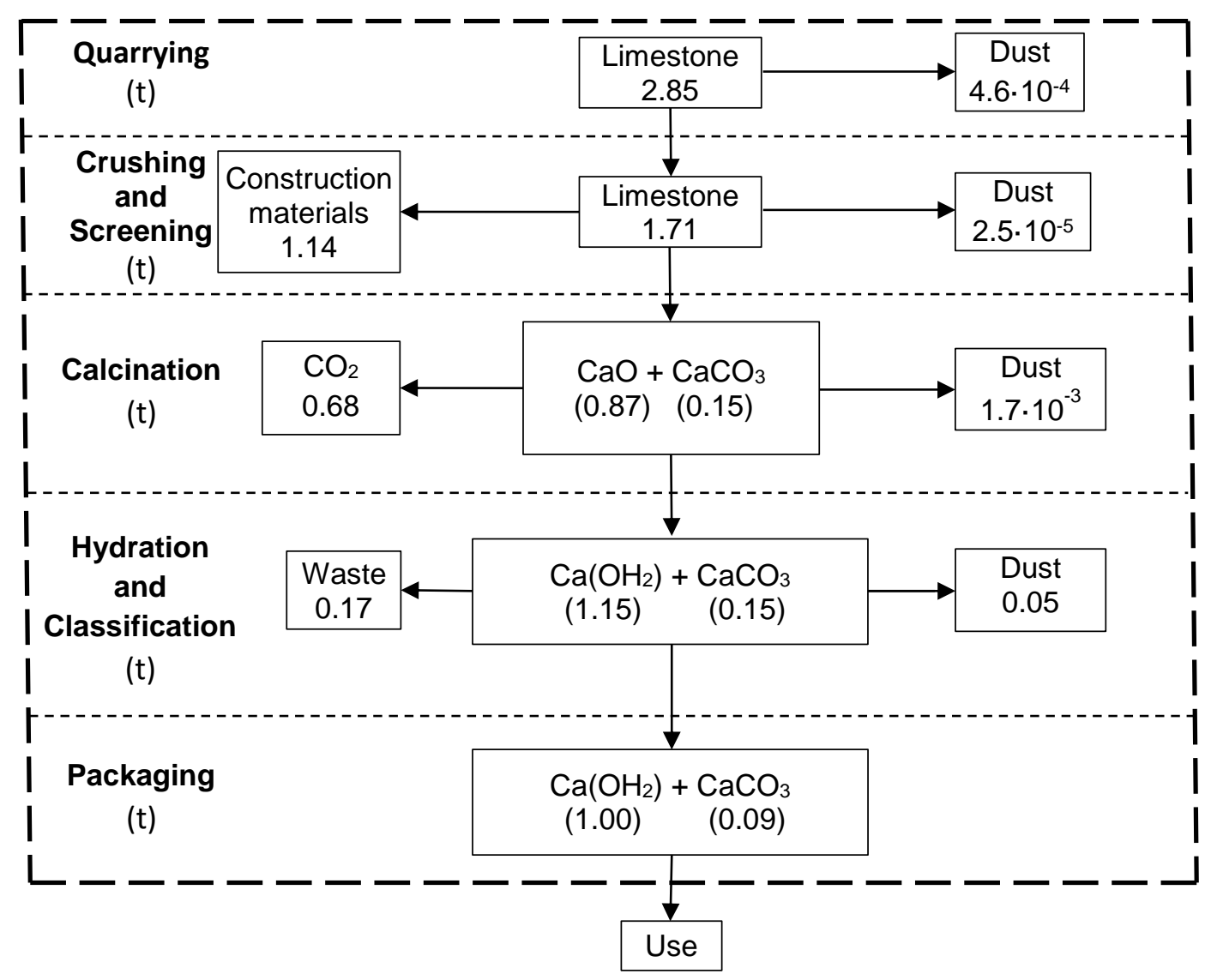

Fig. 3. Mass balance of Cuban plant No.1 per ton of $\mathrm{Ca}(\mathrm{OH})_{2}$ 


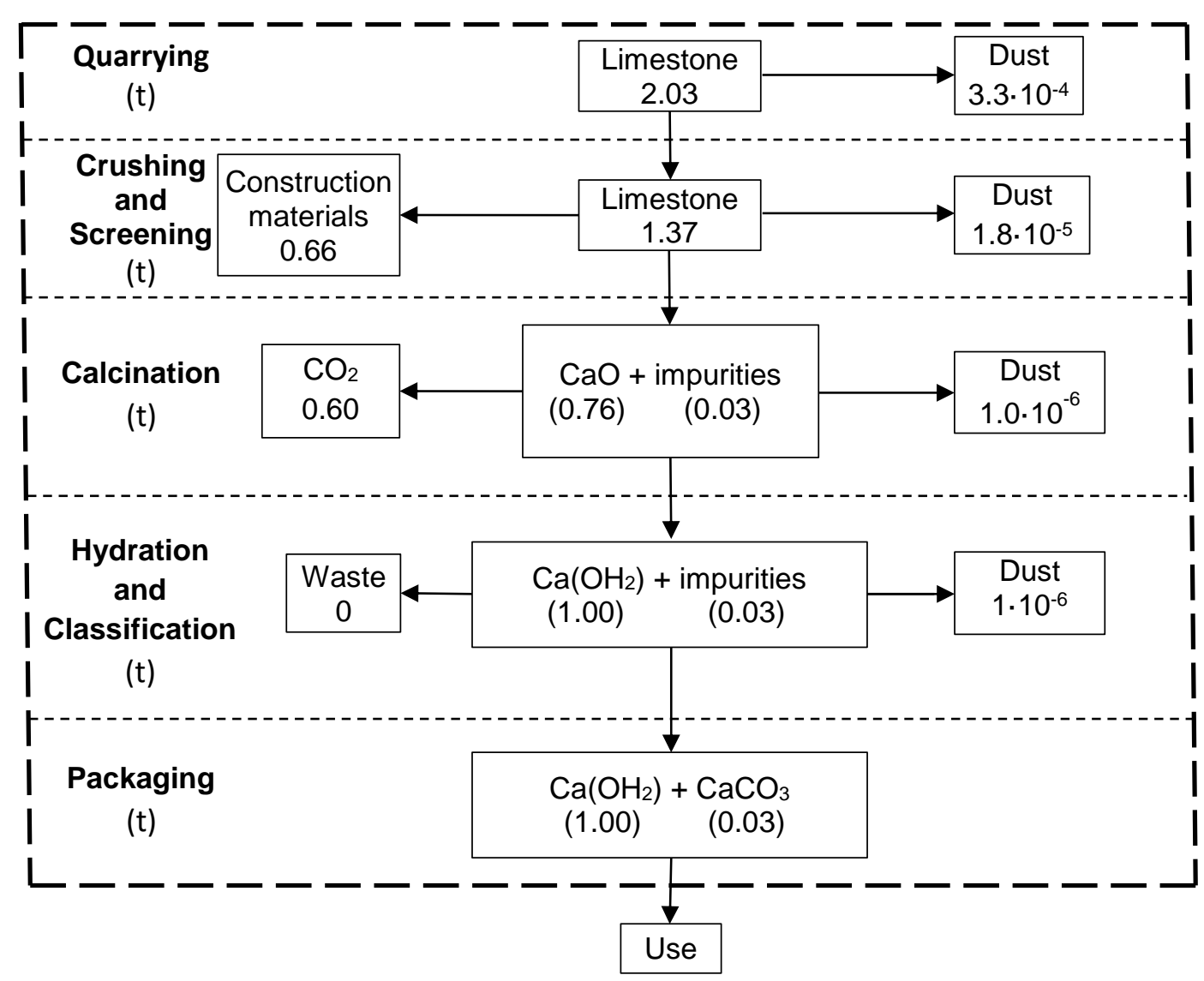

Fig. 4. Mass balance of Kalkfabric Nestal per ton of $\mathrm{Ca}(\mathrm{OH})_{2}$

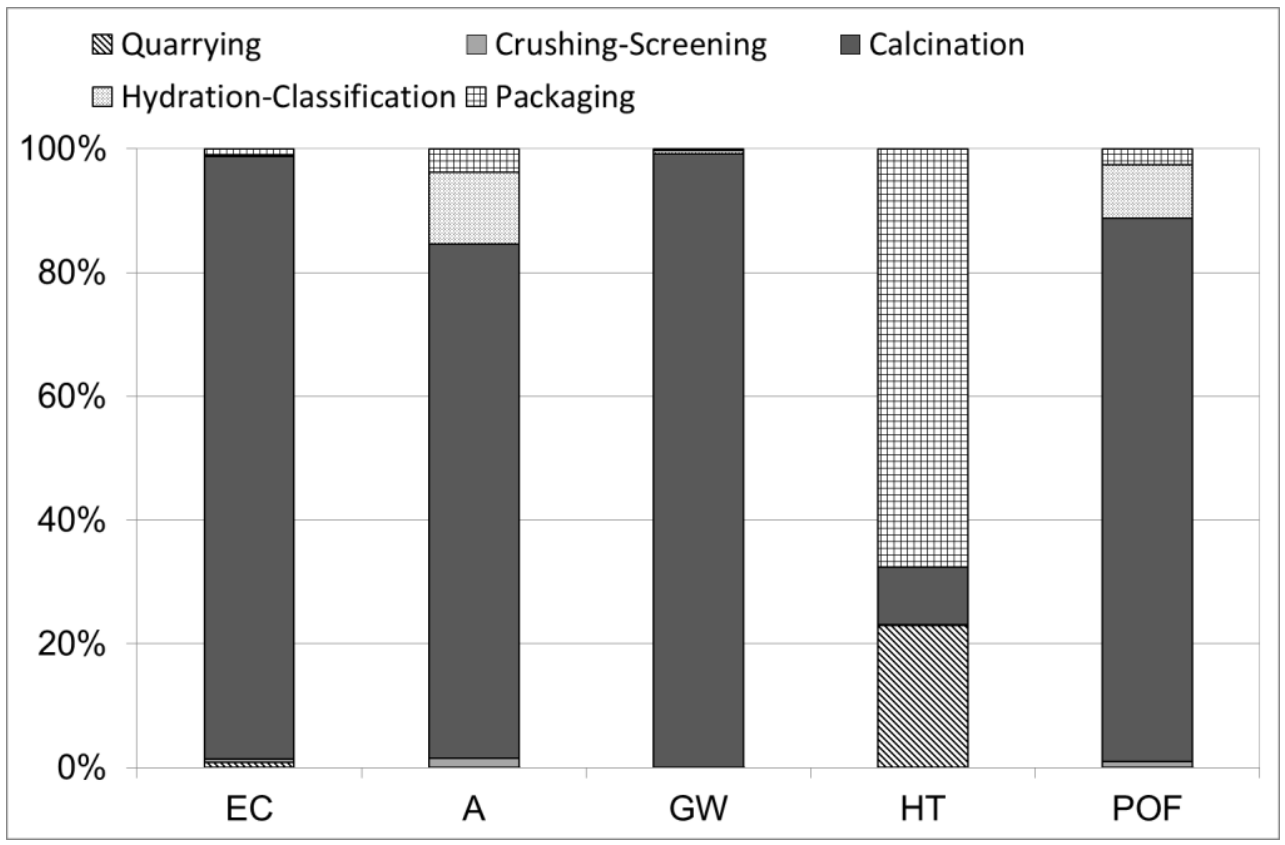

Fig. 5. Relative contributions per production stage to each impact category at KFN 


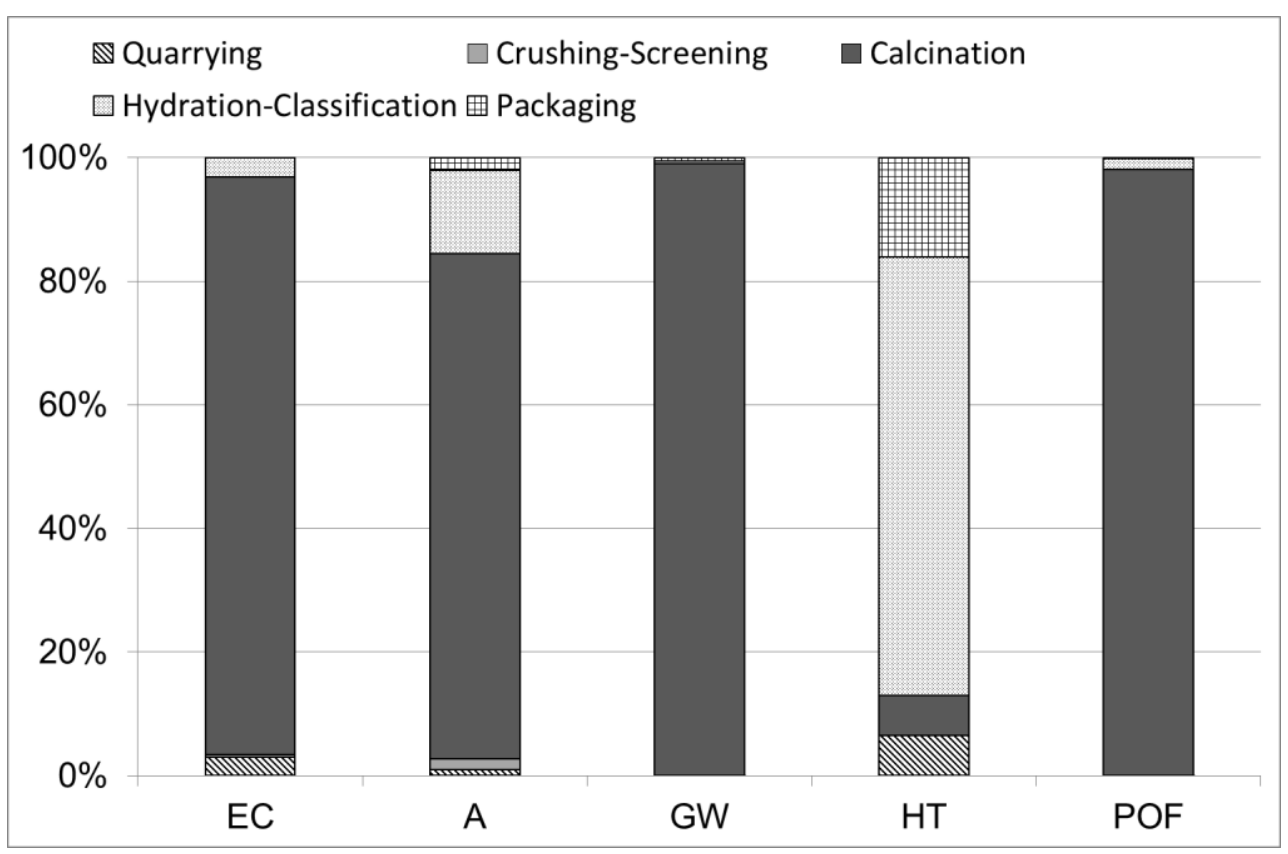

Fig. 6. Relative contribution per production stage to each impact category in plant No.1

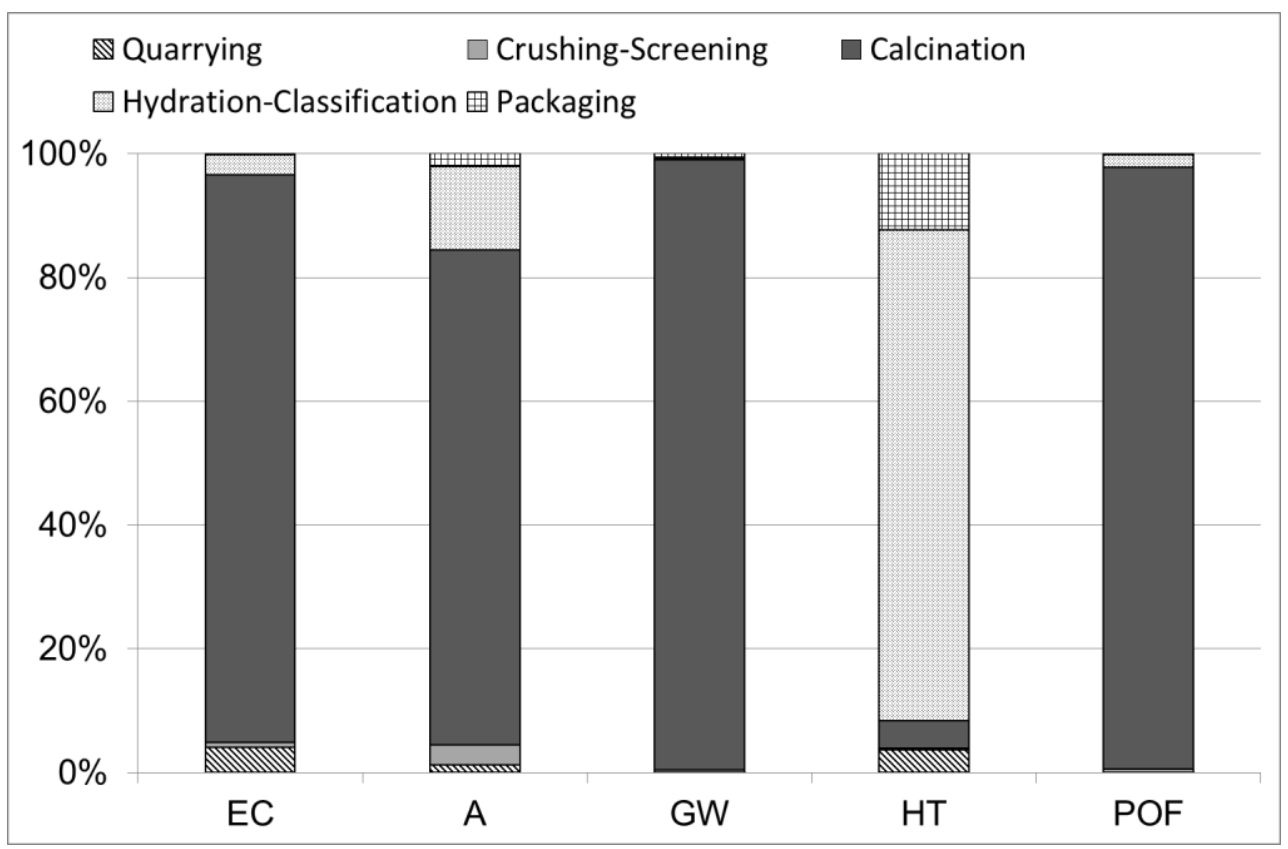

Fig. 7. Relative contribution per production stage to each impact category in plant No.2 


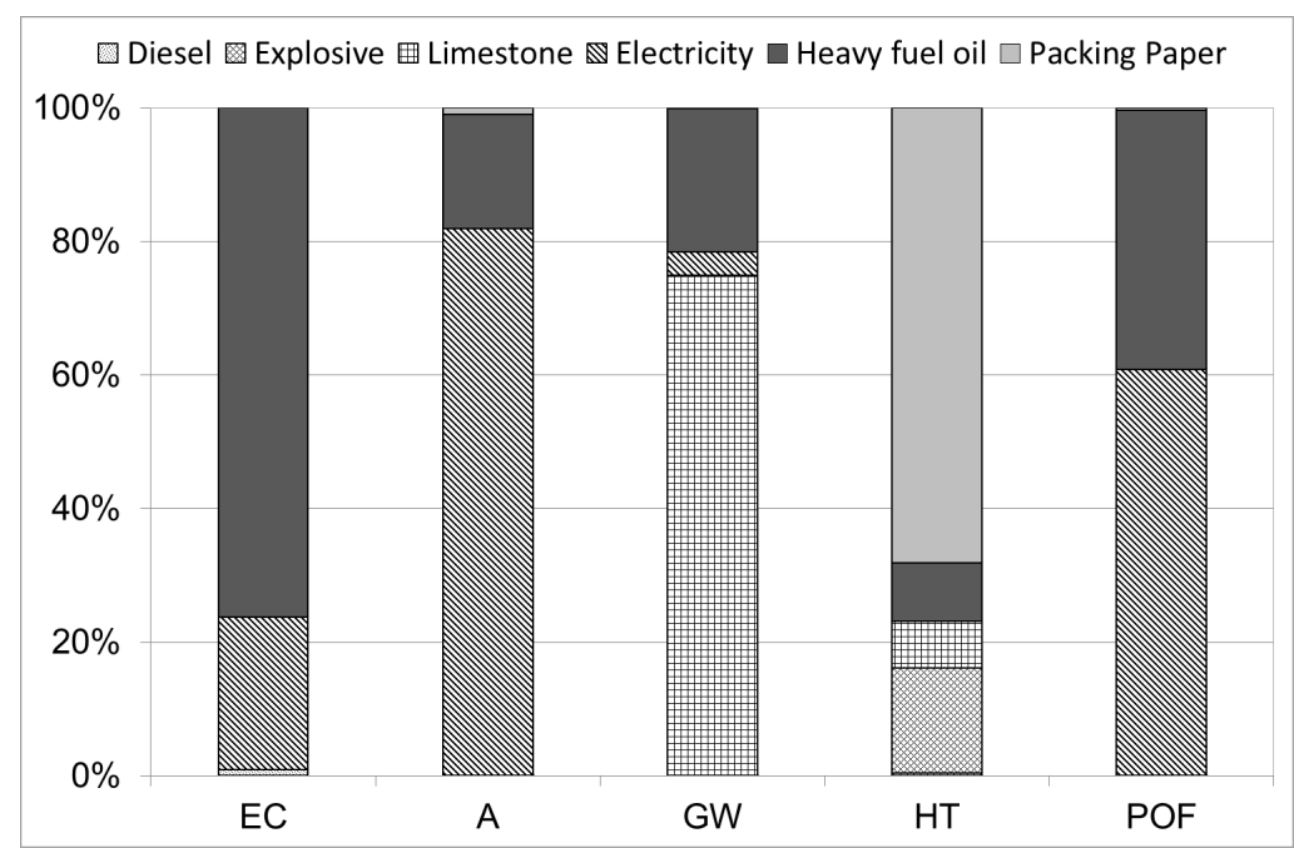

Fig. 8. Relative contribution of each input per impact category in KFN

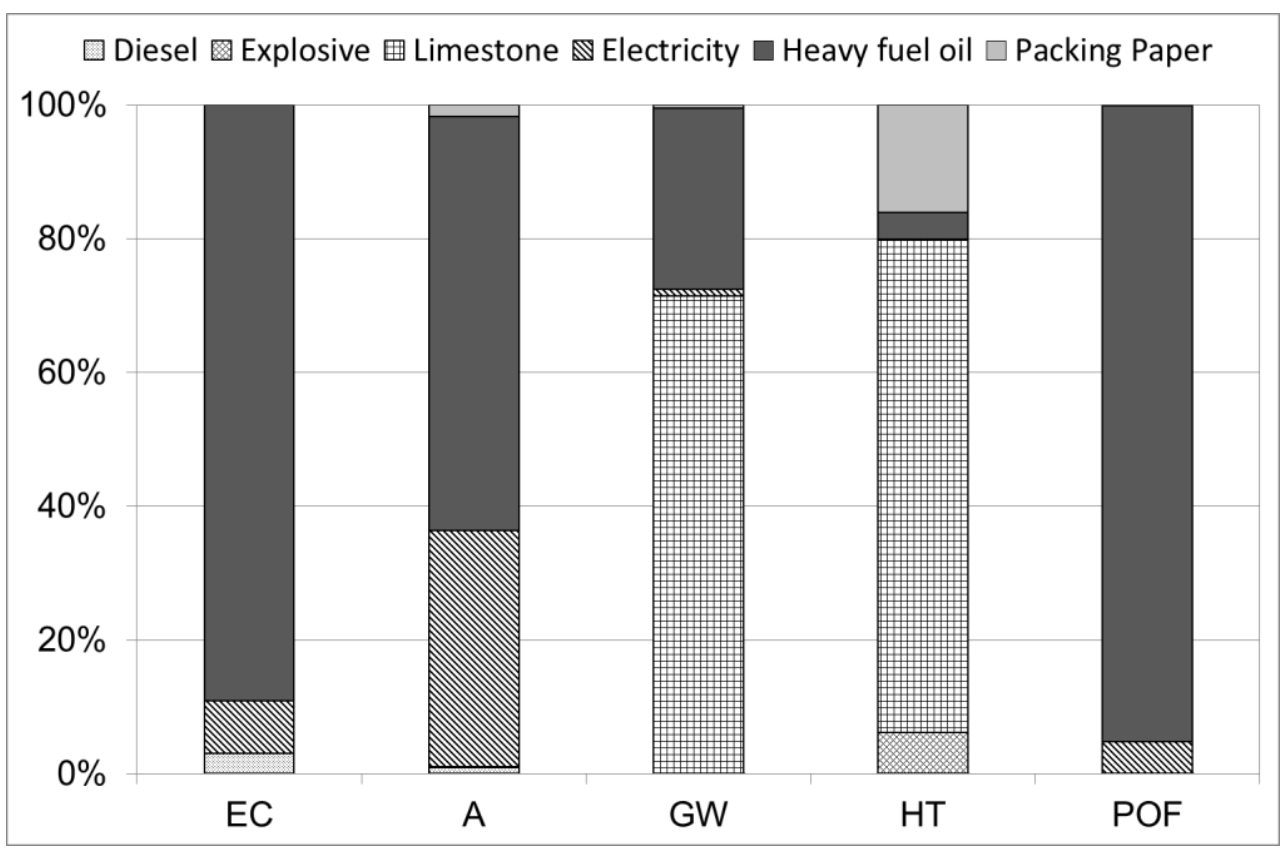

Fig. 9. Relative contribution of each input per impact category in plan No.1 


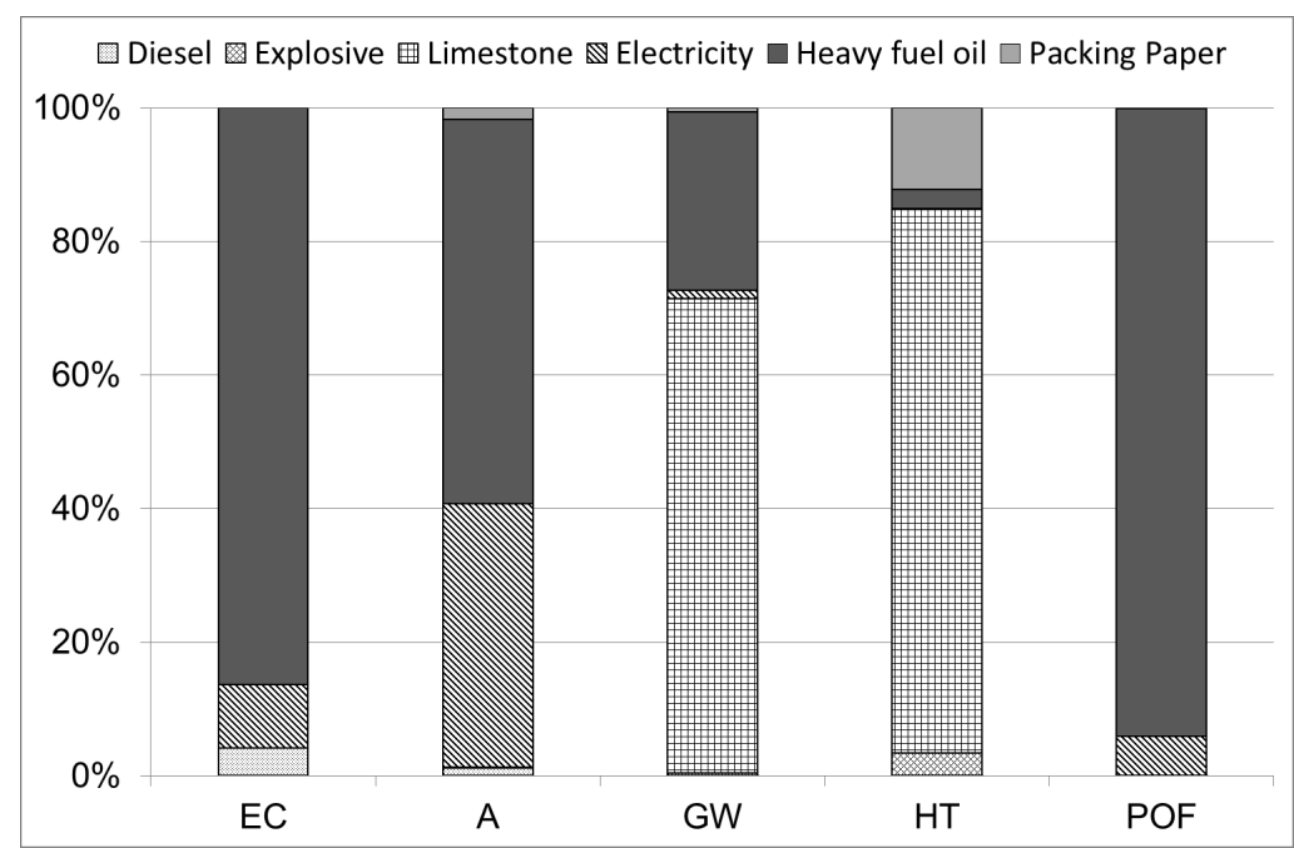

Fig. 10. Relative contribution of each input per impact category in plan No.2

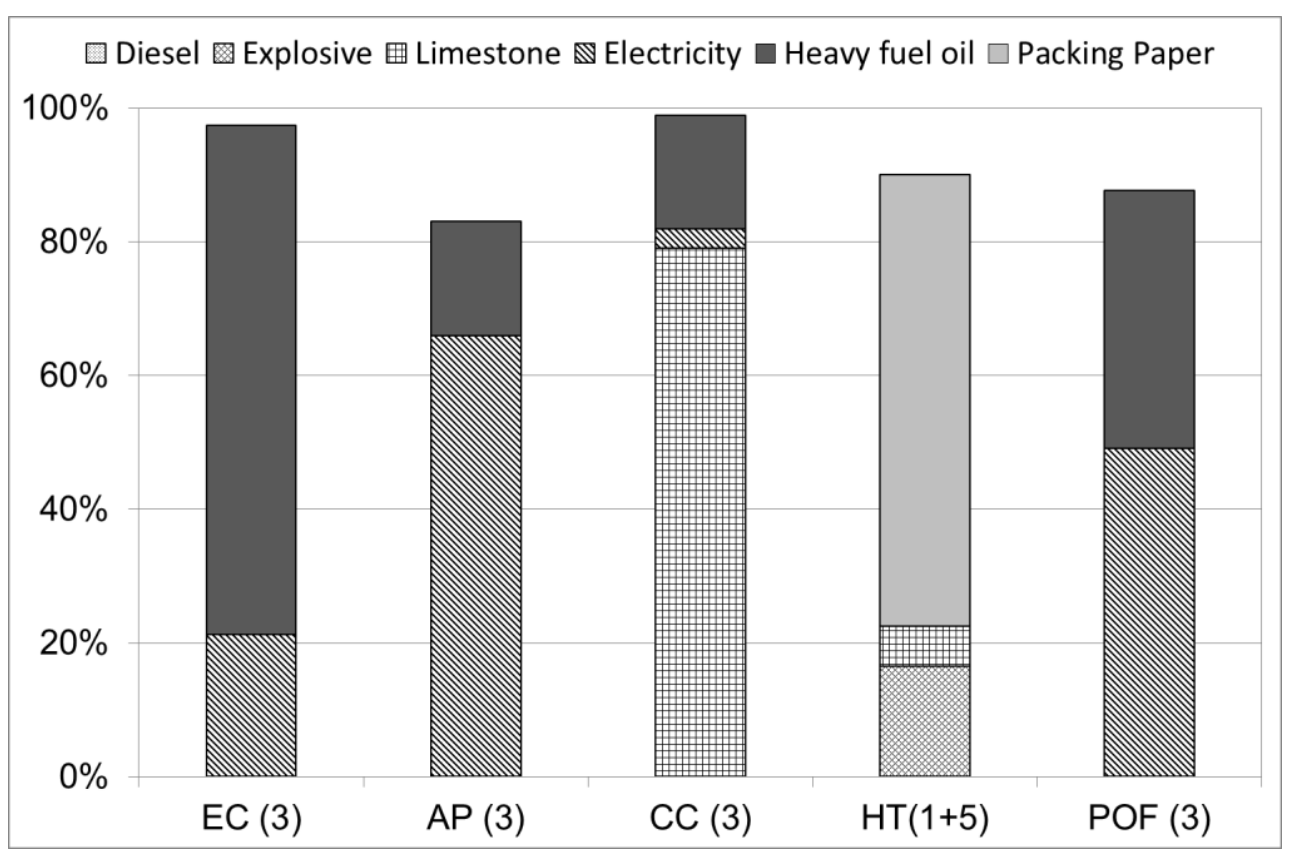

Fig. 11. Relative contributions to the impact in the different impact categories of the most relevant stages and the most significant associated inputs in KFN plant (the numbers within brackets stands for the stages of the process). 


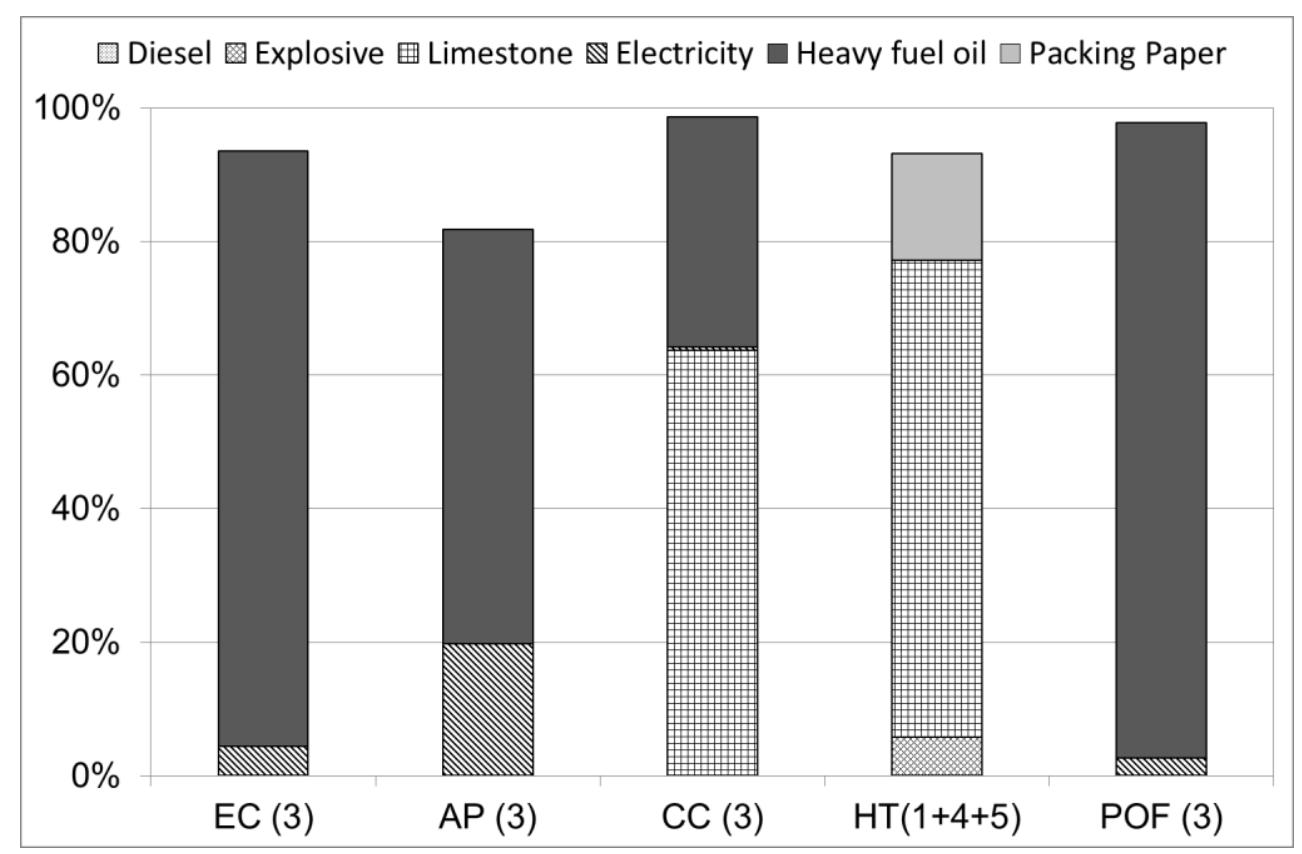

Fig. 12. Relative contributions to the impact in the different impact categories of the most relevant stages and the most significant associated inputs in plant No. 1(the numbers within brackets stands for the stages of the process). 
Tables:

Table 1. Characteristics of the electricity generation in Cuba (per $1 \mathrm{kWh}$ )

\begin{tabular}{|l|l|c|c|}
\hline & & Inputs & Emissions \\
\hline Fossil fuel (MJ) & & $2.7 \cdot 10^{-1}$ & - \\
\hline $\mathbf{C O}_{2}(\mathbf{k g})$ & To air & - & $2.9 \cdot 10^{-1}$ \\
\hline $\mathbf{N O}_{\mathbf{X}}(\mathbf{k g})$ & To air & - & $9.0 \cdot 10^{-4}$ \\
\hline $\mathbf{S O}_{2}(\mathbf{k g})$ & To air & - & $1.8 \cdot 10^{-2}$ \\
\hline Cadmium (kg) & To soil & - & $4.8 \cdot 10^{-11}$ \\
\hline
\end{tabular}

Table 2. Estimated emission values for Cuban plants.

\begin{tabular}{|l|c|c|l|}
\hline Emission & Stage & $\begin{array}{c}\text { Estimation } \\
(\mathrm{kg} / \mathrm{tca}(\mathrm{OH}) 2)\end{array}$ & Reference \\
\hline Dust & 1 & 0.16 & {$[13]$} \\
\hline Dust & 2 & 0.075 & {$[2]$} \\
\hline Dust & 3 & 2 & {$[2],[20]$} \\
\hline $\mathrm{CO}$ & 3 & 50 & {$[2]$} \\
\hline $\mathrm{SO}_{2}$ & 3 & 1 & {$[2],[20]$} \\
\hline $\mathrm{NO} x$ & 3 & 1 & {$[2],[20]$} \\
\hline
\end{tabular}

Table 3. Energy and emissions inventory of the production stages (per ton of $\mathrm{Ca}(\mathrm{OH})_{2}$ ).

\begin{tabular}{|c|c|c|c|c|}
\hline & Units & No.1 & No.2 & KFN \\
\hline \multicolumn{5}{|c|}{1 - Quarrying of limestone } \\
\hline Diesel & MJ & 151 & 225 & 37 \\
\hline Dust & $\mathrm{kg}$ & 0.46 & 0.45 & 0.22 \\
\hline \multicolumn{5}{|c|}{2 - Crushing and screening } \\
\hline Electricity & $\mathrm{kWh}$ & 1.78 & 3.31 & 1.46 \\
\hline Dust & $\mathrm{kg}$ & 0,03 & 0.02 & 0.02 \\
\hline \multicolumn{5}{|l|}{ 3-Calcination } \\
\hline Fuel oil & MJ & 4481 & 4028 & 2837 \\
\hline Electricity & $\mathrm{kWh}$ & 19.8 & 22.8 & 37.5 \\
\hline $\mathrm{CO}_{2}$ & $\mathrm{~kg}$ & 973 & 895 & 721 \\
\hline $\mathrm{CO}$ & $\mathrm{kg}$ & 58.8 & 55.6 & 3.78 \\
\hline $\mathrm{SO}_{2}$ & $\mathrm{~kg}$ & 0.87 & 0.82 & 0.27 \\
\hline $\mathrm{NOx}$ & $\mathrm{kg}$ & 0.87 & 0.82 & 0.27 \\
\hline Dust & $\mathrm{kg}$ & 1.74 & 1.63 & 0.06 \\
\hline \multicolumn{5}{|c|}{4 - Hydration and classification } \\
\hline Electricity & kWh & 13.6 & 13.7 & 13.1 \\
\hline Dust & $\mathrm{kg}$ & 51 & 76 & 0.001 \\
\hline \multicolumn{5}{|l|}{5 - Packaging } \\
\hline Electricity & kWh & 0.3 & 0.3 & 3.2 \\
\hline Packing bags & $\mathrm{kg}$ & 4.6 & 4.5 & 4.4 \\
\hline
\end{tabular}

Table 4. Impact assessment of the lime production process (per ton of $\left.\mathrm{Ca}(\mathrm{OH})_{2}\right)[20]$

\begin{tabular}{|l|c|r|r|r|}
\hline \multicolumn{1}{|c|}{ Impact } & Units & No.1 & \multicolumn{1}{c|}{ No.2 } & \multicolumn{1}{c|}{ KFN } \\
\hline Energy consumption & $\mathrm{MJ}$ & 5026 & 4473 & 3893 \\
\hline Acidification & $\mathrm{kg}-\mathrm{SO}_{2}$-eq. & 2.4 & 2.4 & 2.7 \\
\hline Global Warming & $\mathrm{kg}-\mathrm{CO}_{2}$-eq. & 1072 & 986 & 756 \\
\hline Human Toxicity & $\mathrm{kg} 1$ 1.4-dichlorobenzene eq. & 28 & 37 & 4.20 \\
\hline $\begin{array}{l}\text { Photo Oxidant } \\
\text { Formation }\end{array}$ & $\mathrm{kg}$ 1.4-ethylene eq. & 1.5 & 1.3 & 0.3 \\
\hline
\end{tabular}


Table 5. Production cost of 1 ton of hydrated lime.

\begin{tabular}{|l|c|}
\hline Plant & $\begin{array}{c}\text { Production cost } \\
(\$ / \mathrm{t} \mathrm{Ca}(\mathrm{OH}) 2)\end{array}$ \\
\hline No.1 & 79.55 \\
\hline No.2 & 73.52 \\
\hline KFN & 56.69 \\
\hline
\end{tabular}

Table 6. Saving potential associated with reduction of $\mathrm{CO}$ emission.

\begin{tabular}{|c|c|c|c|}
\hline Plant & $\begin{array}{c}\text { Fuel saving potential } \\
\left(\mathrm{kg} \mathrm{fue}_{\mathrm{t}} / \mathrm{ta}_{(\mathrm{OH}) 2)}\right.\end{array}$ & $\begin{array}{c}\text { Reduction of CO emission } \\
\left(\mathrm{kg} / \mathrm{t}_{\mathrm{Ca}(\mathrm{OH}) 2}\right)\end{array}$ & $\begin{array}{c}\text { Saving } \\
\left(\$ / \mathrm{t}_{\mathrm{Ca}(\mathrm{OH}) 2}\right)\end{array}$ \\
\hline No.1 & 13.61 & 46 & 8.51 \\
\hline No.2 & 12.78 & 40 & 7.99 \\
\hline
\end{tabular}

Table 7. Saving potential associated with the emission of $\mathrm{CO}_{2}$.

\begin{tabular}{|c|c|c|c|}
\hline Plant & $\begin{array}{c}\text { Fuel saving Potential } \\
\left(\mathrm{kg} \text { fue/ } / \mathrm{ta}_{(\mathrm{OH}) 2}\right)\end{array}$ & $\begin{array}{c}\text { Reduction of } \mathbf{C O}_{2} \text { emission } \\
\left(\mathrm{kg}_{\mathrm{CO} 2} / \mathrm{tca}_{\mathrm{O}(\mathrm{H}) 2}\right)\end{array}$ & $\begin{array}{c}\text { Saving } \\
\left(\$ / \mathrm{tca}_{(\mathrm{OH}) 2}\right)\end{array}$ \\
\hline No.1 & 40.09 & 125.96 & 25.06 \\
\hline No.2 & 28.77 & 90.38 & 17.98 \\
\hline
\end{tabular}

Table 8. Saving potential associated with the loss of product

\begin{tabular}{|l|c|c|}
\hline Plant & $\begin{array}{c}\text { Product loss } \\
\left(\mathrm{kgCa}(\mathrm{OH}) 2 / \mathrm{t}_{\mathrm{Ca}(\mathrm{OH}) 2)}\right)\end{array}$ & $\begin{array}{c}\text { Saving } \\
\left(\$ / \mathrm{t}_{\mathrm{Ca}(\mathrm{OH}) 2)}\right.\end{array}$ \\
\hline No.1 & 150.18 & 10.48 \\
\hline No.2 & 76.31 & 5.28 \\
\hline
\end{tabular}

